\title{
Some Particular Observations on Diurnal Phase Variations of VLF Transmissions Received in Paris
}

\author{
B. Decaux and A. Gabry \\ Contribution From Centre National d'Etudes des Télécommunications, Paris-Bagneux, France

\begin{abstract}
Observations made in Paris, France, of the phase of various frequency stabilized VLF transmitters are reported. Descriptions are given of the seasonal dependence of the diurnal phase shift on an arctic path, effects following solar flares, effects of two solar eclipses, and observation following the high-altitude nuclear explosion of July 9, 1962.
\end{abstract}

For some years the CNET Frequency Department has continuously recorded the phase of the stabilized VLF transmissions. The initial aim of this recording was to compare the CNET's Atomichron standard to atomic standards of other laboratories in the world. Afterwards, interesting researching research on perturbations caused to the transit-time of the transmissions by the propagation phenomena, led to an extension of the equipment. The recordings were made at first on GBR $16 \mathrm{kc} / \mathrm{s}$, and successively on other transmissions when they were stabilized. At the present time, six transmissions are recorded:

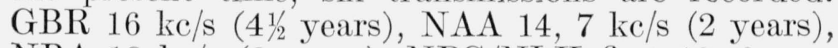
NBA $18 \mathrm{kc} / \mathrm{s}$ (3 years), NPG/NLK first 18, 6 now $24 \mathrm{kc} / \mathrm{s}$ (2 years), NPM 19, $8 \mathrm{kc} / \mathrm{s}$ (2 years), and NSS $22,3 \mathrm{kc} / \mathrm{s}$ (2 years). The recording of NPM is almost unusable in summer, because of the very poor signal-to-noise ratio. The recording equipment uses a servo phase-follower and synchronous detection. In addition to the phase recording, the amplitude of the signals is also recorded.

The various well-known forms of the phase curves related to the hours and the seasons were clearly observed on all the transmissions. This paper will, however, deal only with departures observed during particular geographic situations and ionospheric phenomena.

First, 3 years of recording of NBA transmissions give a good knowledge of the seasonal evolution of the variations at the time of sunrise and sunset [Decaux et al., 1961a and 1963b]. It is well known that the received phase changes quickly when the sun rises in each reflection point in the $D$-region, and remains nearly constant during the transition of the shadow line from one reflection point to the other [Rieker, 1963]. The variation at the sunset is more progressive.

We have compared the observed and calculated values of the time interval between the successive points. The observed values are deduced from experimental curves by averaging on several consecutive days. The calculated values take into account the progressive shifting of the ground reflection points, and also the influence of the ozone layer. The differences between observed and calculated values, for various typical epochs of the seasons, do not generally exceed $5 \mathrm{~min}$.

It is interesting to note that the amplitude of phase variation between night and day changes slightly from season to season: $70 \mu \mathrm{sec}$ at winter solstices, $80 \mu \mathrm{sec}$ at summer solstices, $75 \mu \mathrm{sec}$ at equinoxes. The waves path at night would be about 200 $\mathrm{km}$ greater than the length of the great circle Balboa-Bagneux.

The NPM and NPG/NLK paths cross a part of arctic polar regions. The interpretation of NPM phase curves is uncertain because of the low signa strength, but the NPG/NLK records are excellent [Decaux et al., 1963c]. The Jim Creek-Paris path cross the polar region on about $2,000 \mathrm{~km}$ (1/4 of the total length). Therefore one observes the well known "double humped" curves, since the part o path crossing the polar region are, according to the season, continually in light, or continually in dark. Moreover this path has an interesting peculiarity: both extremities have nearly equal latitudes (Jim Creek: $48^{\circ} 12^{\prime}$, Bagneux: $\left.48^{\circ} 46^{\prime}\right)$. Then the part of the great circle beyond the polar circle is in the middle of the total path, and the $60^{\circ} \mathrm{W}$ meridian is an axis of symmetry (fig. 1).

Near 0400 U'T, the path is thus entirely in dark at every time of year, except from the end of April to the middle of August. Between those two limits, the wave path pass progressively, on all its length, from night to day and vice-versa. Then the phase curves have the characteristic forms, successively indicated in figure 2 , and explained below.

At spring equinox (fig. 2a) the form is the classic trapezium. At the beginning of May (fig. 2b) the night effect (peak) lasts for very short time near 0400 U'T. In the middle of May (fig. 2c) a daylight effect (dip) appears near 0400 UT. From the beginning of June till nearly the 10th of July (fig. $2 d$ ), the daylight effect is complete at 0400 . Near the 1st of August the day and night effects are practically equal (fig. 2e); then one observes, during a very few days, a fast inversion, from the 0400 (dip) to a peak. The figure $2 f$ and $2 \mathrm{~g}$ shows the curves are practically inverted around the 20th of August and the 20th of December. In August, the curve 


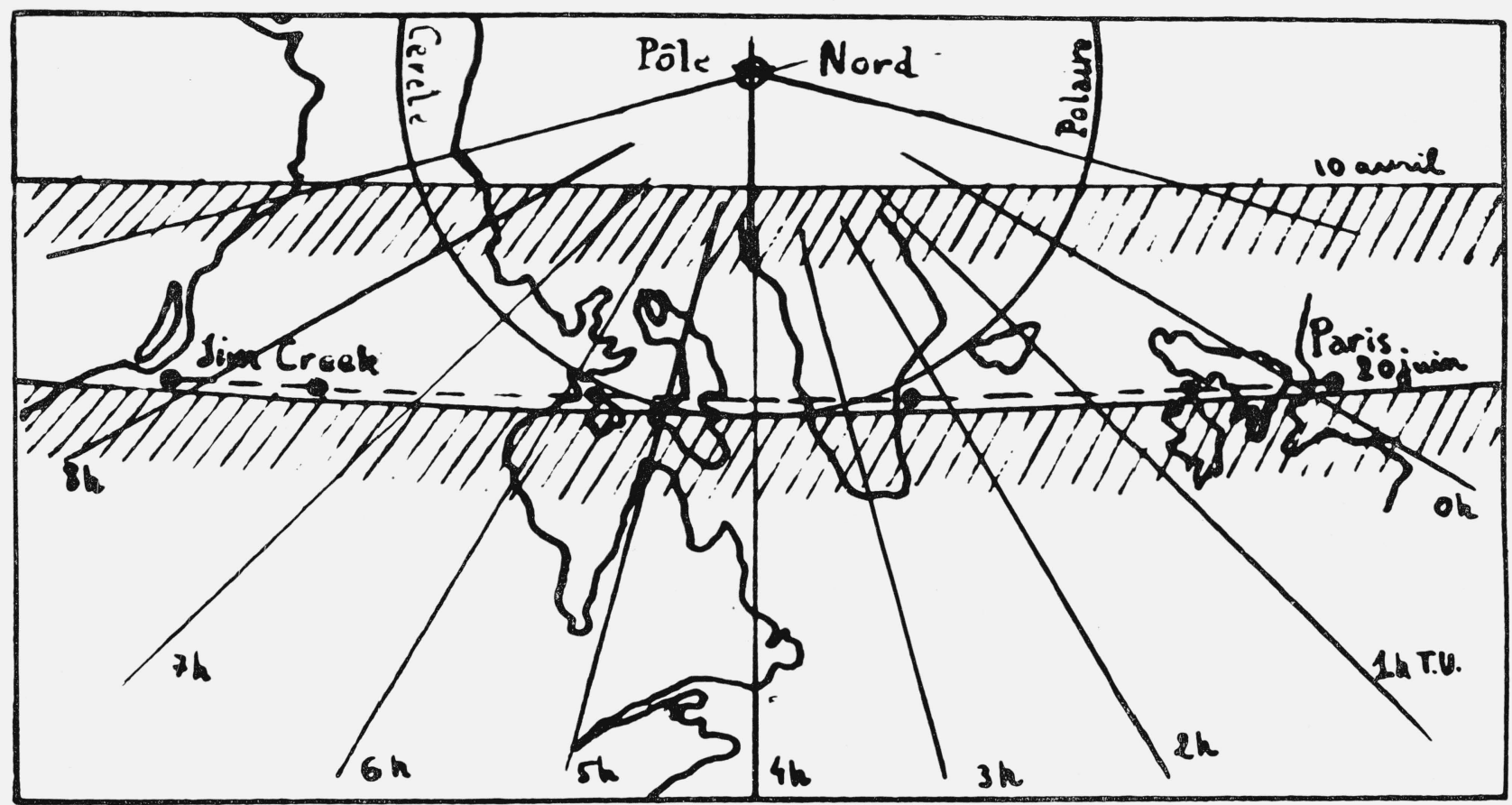

Figure 1. The NPG/NLK to Paris path.

shows a peak of 0400 (a short instant in total dark), in December shows a dip at 1600 U'T (a short instant in total light). The dissymmetry of characteristic dates referring to the solstices can be explained by the displacement of the shadow-line in the $D$ layer, in comparison with the shadow-line on the ground, of about $500 \mathrm{~km}$ towards the night side.

Some sudden ionospheric disturbances have been observed [Decaux and Gabry, 1961b]. A fast phase advance appears generally at the beginning of disturbance. Moreover we have observed at different times, a day and a half or 2 days afterwards, phase undulations with about 2 -hr periods. One observed such undulations, during night, for GBR on the 13th of November 1960 and for NBA on the 28th of March 1961. The multiple disturbances of the 23d and 25th of May 1963 have produced phase advances of 5 to $25 \mu$ sec depending on the transmission being observed. Moreover, NBA has shown on the 25th of May similar undulations, but during daylight.

The solar eclipses effects, on the 15th of February 1961 [Decaux et al., 1961c] and on the 20th of July 1963 , were carefully studied. On the 15 th of February 1961 we carried the recording equipment for GBR and NBA to southern France, in the totality zone. The GBR wave path was practically in daylight, but $2 / 3$ of the NBA path was still dark. At the time of the eclipse, the phase recovered, for the two transmissions to a value nearly equal to the night value (fig. 3). We must remark that the maxi- mum of the effect on NBA took place a few minutes before the maximum of the eclipse on the ground, and on GBR a few minutes after this maximum; the difference between the two maxima was about 10 $\min$.

On the 20th of July 1963, the eclipse crossed the wave paths of the five American transmissions. The NPM reception was too weak for use. The NBA transmissions was unfortunately broken off from 2040 to 2200 U'T, just during the eclipse, preventing any observation. The NPG/NLK $(24 \mathrm{kc} / \mathrm{s})$ phase variation, normally existing near 2100 U'T, was six times greater during the eclipse (delay: about $10 \mu \mathrm{sec})$; moreover, the reception strength was about twice its normal value (fig. 4). The NAA phase was about $8 \mu$ sec late during the maximum of the eclipse. On NSS the influence of the eclipse was not noticeable.

The high altitude thermonuclear explosion on the 9th of July 1962 produced a very large variation of amplitude and phase on all VLF waves. The phase advance was $10 \mu$ sec for NAA and NPG/NLK, and $35 \mu \mathrm{sec}$ for $\mathrm{NBA}$, about a third of the normal daily variation in this season (fig. 5). The NBA amplitude increased suddenly simultaneously with the phase change. GBR waves received in Paris are always a combination between the groundwave and the ionospheric wave; then the phenomena are somewhat complicated. On the 9th of July 1962, the GBR phase was delayed by $18 \mu \mathrm{sec}$. It is to note that the nearest point of the path was at $12,200 \mathrm{~km}$ from the explosion [Decaux et al., 1963a]. 


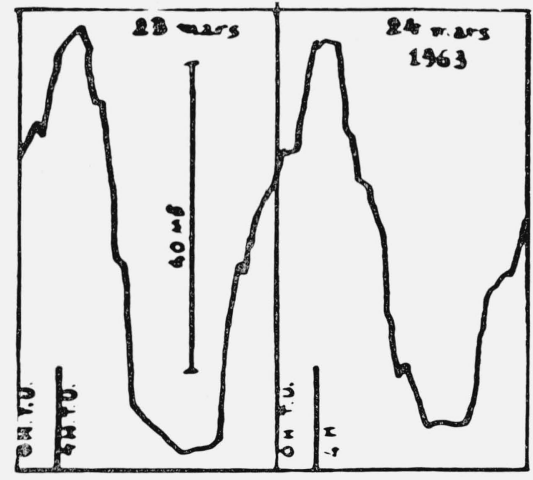

a)

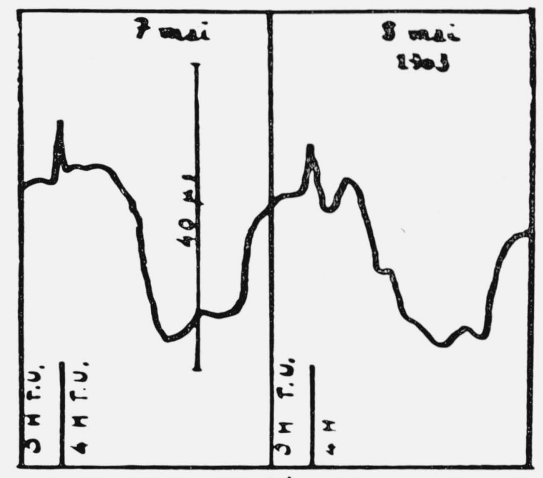

8)

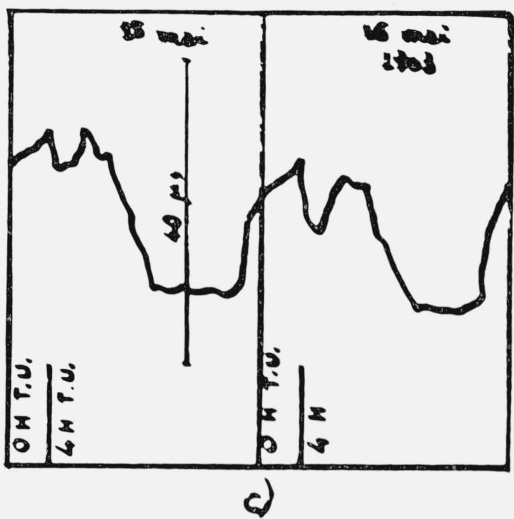

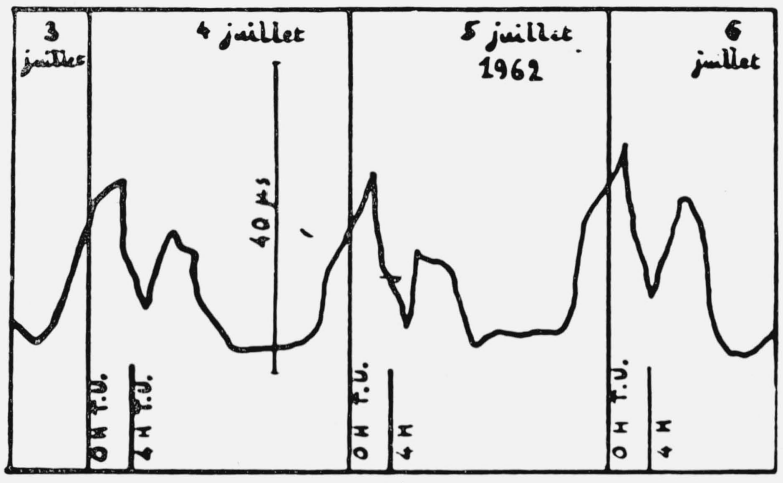

d)

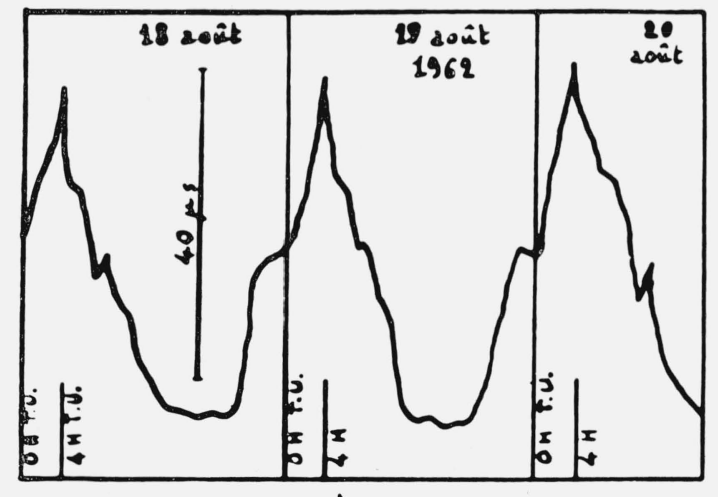

f)

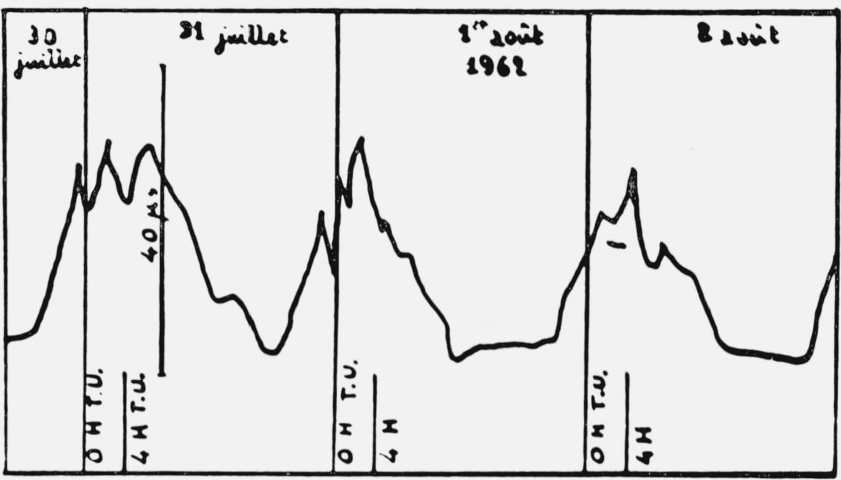

e)

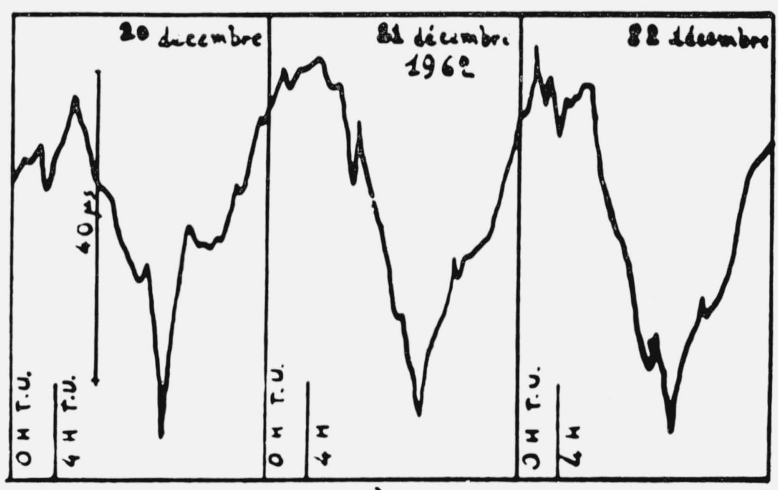

g)

Figure 2. The seasonal evolution of the diurnal phase shift of NPG/NLK observed in Paris.

All those phenomena appeared about 2 to $3 \mathrm{~min}$ after the explosion. They lasted $3 \mathrm{hr}$ for NPG/ NLK, $6 \mathrm{hr}$ for NAA and NBA, $10 \mathrm{hr}$ for GBR; those last periods are roughly in proportion to the distance between explosion and each transmitter.

On the 20th and 26th of October and on the 1st of November 1962, explosions (below $D$ layer) produced phase advances, on NPM waves only, reaching up to $20 \mu \mathrm{sec}$ and quickly recovering.
Preliminary simultaneous recording experiments, with common local phase reference, was developed between Bagneux and the Meudon Observatory (distance $6 \mathrm{~km}$ ) on the NBA transmission. Some of phase difference discrepancies were observed.

Several phase recording equipments for VLF transmissions are planned by CNET in other areas of the world, principally in central Africa, Kerguelen Islands, and Terre Adelie (Antarctic) in relation with the I.Q.S.Y. 


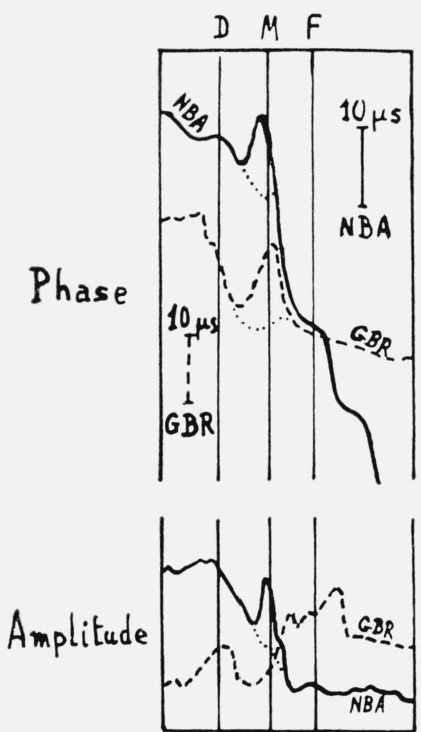

FIgURE 3. Observations during the eclipse of 15 February 1961. (The dotted lines show the normal behavior.)

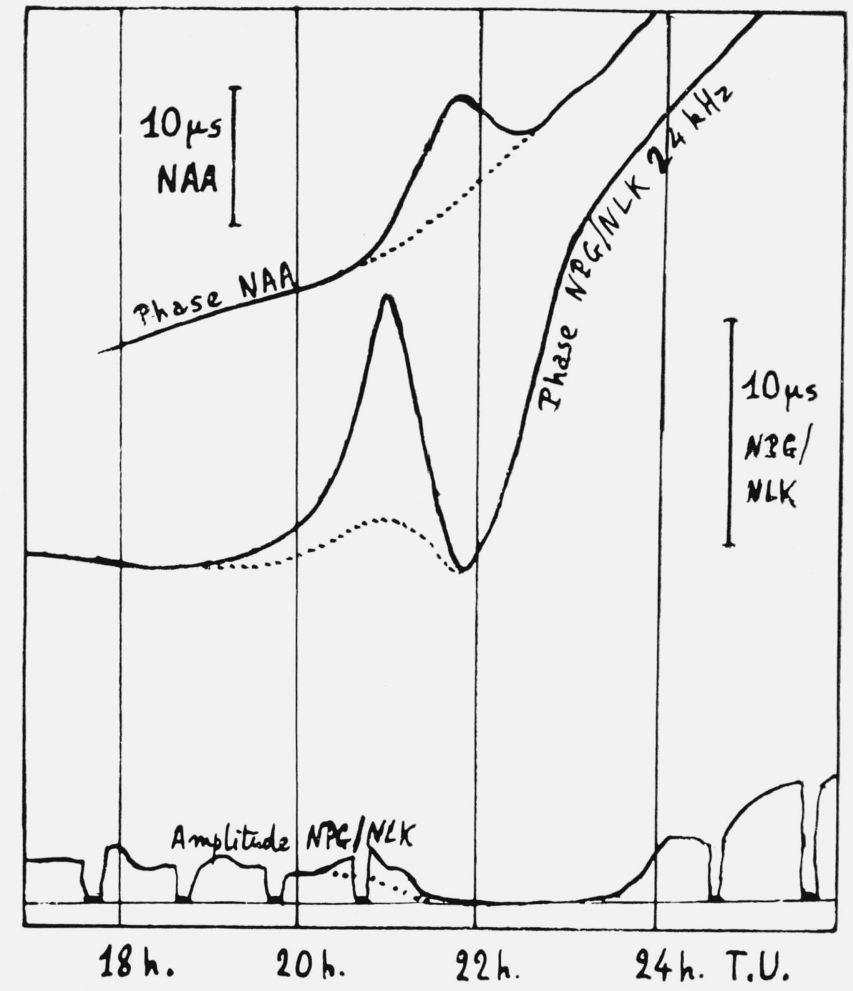

FIGURE 4. Observations during the eclipse of 20 July 1963. (The dotted lines show the normal behavior.)
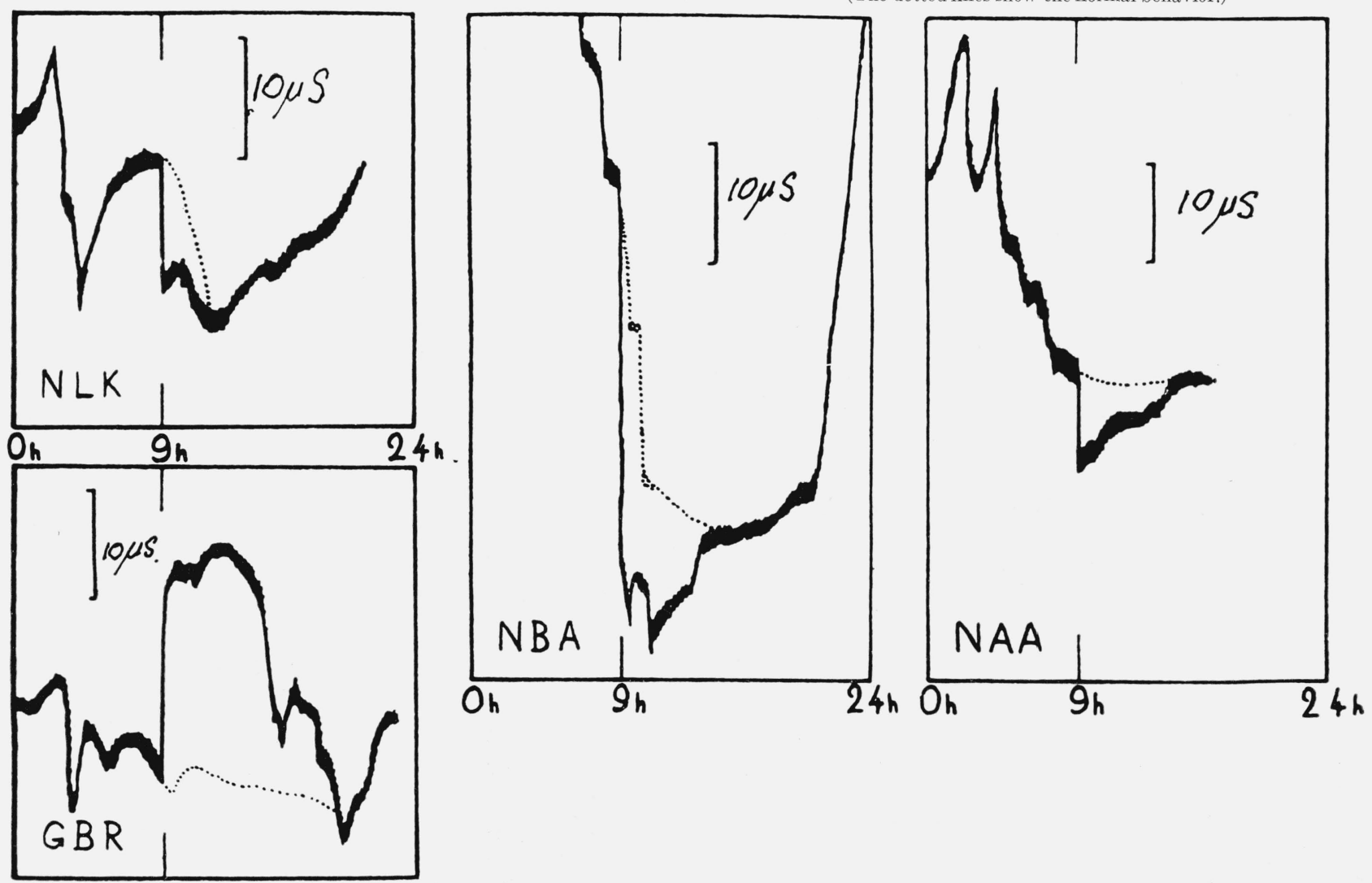

Figure 5. Observations on July 9, 1962.

(The dotted lines show normal behavior.) 


\section{References}

Decaux, B., A. Frances, and A. Gabry (Dec. 1961a), Influence des conditions géographiques et saisonnières sur la variation diurne de la durée de trajet des ondes myriamétriques, Compt. Rend. Acad. Sci. 253, 2877-2879.

Decaux, B., and A. Gabry (Apr. 1961b), Variation diurne de la durée de trajet des ondes myriamétriques, Compt. Rend. Acad. Sci. \%52, 2187-2189.

Decaux, B., A. Gabry, J. Lachatre, and J. Lucas (Apr. 1961c), Influence de l'éclipse totale de soleil du 15 février p. 961 sur la durée de trajet des ondes myriamétriques, Compt. Rend. Acad. Sci. 252, 2387-2389.

Decaux, B., A. Frances, A. Gabry, and M. Reyssat (Jan. 1963a), Perturbations produites par les explosions thermonucléaires en haute altitude (plus particulierement celle du 9 juillet 1962) dans la durée de trajet et l'ampli- tude des ondes myriamétriques, Compt. Rend. Acad. Sci. 256, 481-484.

Decaux, B., A. Frances, A. Gabry (Jan. 1963b), Evolution saisonnière de la variation diurne de la phase des ondes myriamétriques sur le trajet Panama-Bagneux, Compt. Rend. Acad. Sci. 256, 742-744.

Decaux, B., A. Frances, and A. Gabry (July 1963c), Changements rapides dans le régime saisonnier de la variation diurne de la durée d'un trajet d'ondes myriamétriques passant au-delá du cercle polaire, Compt. Rend. Acad. Sci. 25\%.

Rieker, J. (Mar.-Apr. 1963), Sunset and sunrise in the ionosphere: effects on propagation of long waves, J. Res. NBS 6\%D (Radio Prop.), No. 2, 119-138.

(Paper 68D1-312) 